\title{
Do Obligations Follow the Mind or Body?
}

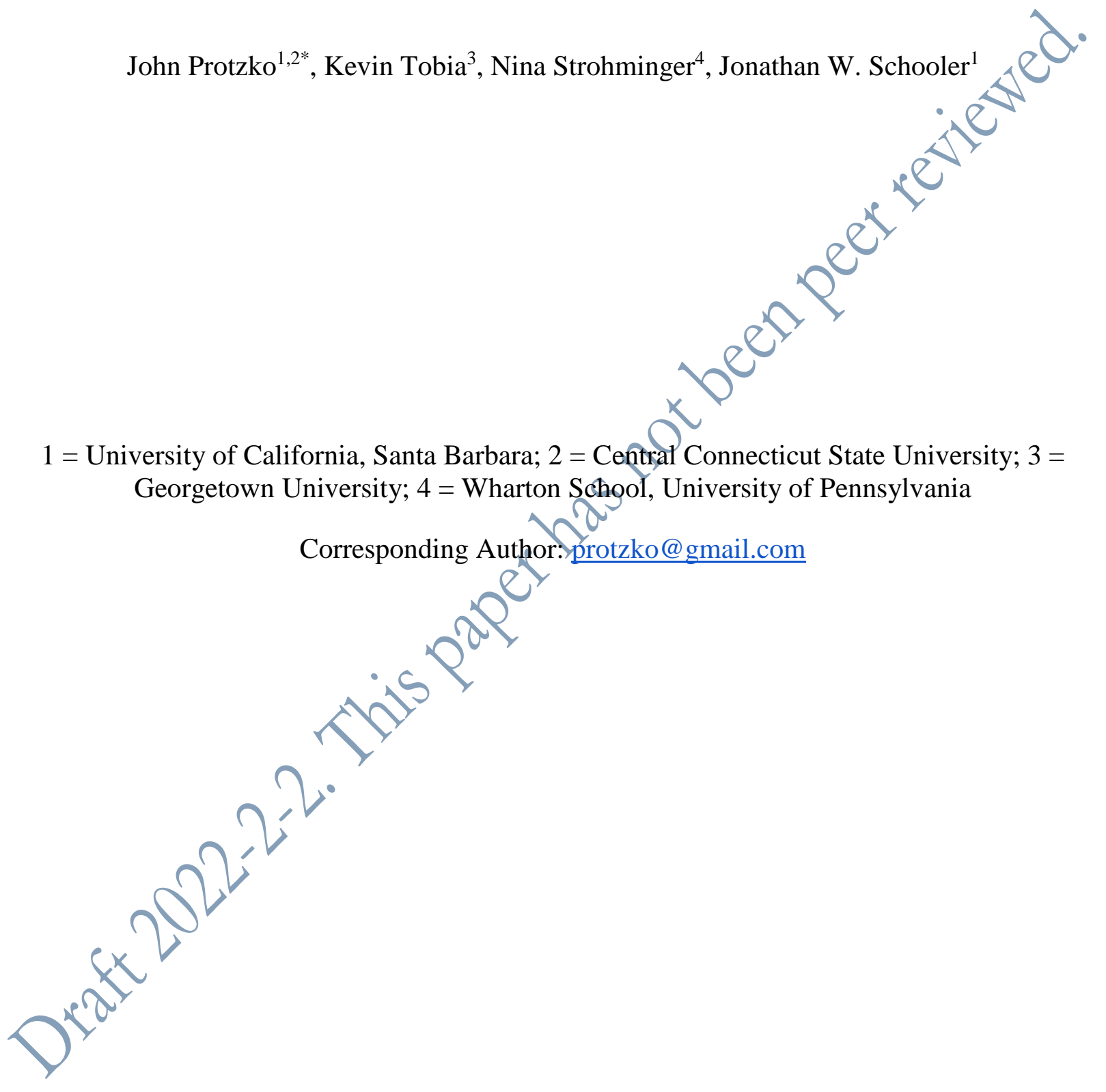




\begin{abstract}
Do you persist as the same person over time because you keep the same mind or because you keep the same body? Philosophers have long investigated this question of personal identity with thought experiments. Cognitive scientists have joined this tradition by assessing lay intuitions about those cases. Much of this work has focused on judgments of identity continuity. But identity also has practical significance: obligations are tagged to one's identity over time. Understanding how someone persists as the same person over time could provide insight into how and why moral and legal obligations persist. In this paper, we investigate judgments of obligations in hypothetical cases where a person's mind and body diverge (e.g., brain transplant cases). We find a striking pattern of results: In assigning obligations in these identity test cases, people are divided among three groups: "body-followers", "mind-followers", and splitters"people who say that the obligation is split between the mind and the body. Across studies, responses are predicted by a variety of factors, including mind/body dualism, essentialism, education, and professional training. When we give this task to professionallawyers, accountants, and bankers, we find they are more inclined to rely on bodily continuity in tracking obligations. These findings reveal not only the heterogeneity of intuitions about identity, but how these intuitions relate to the legal standing of an individual's obligations.
\end{abstract}

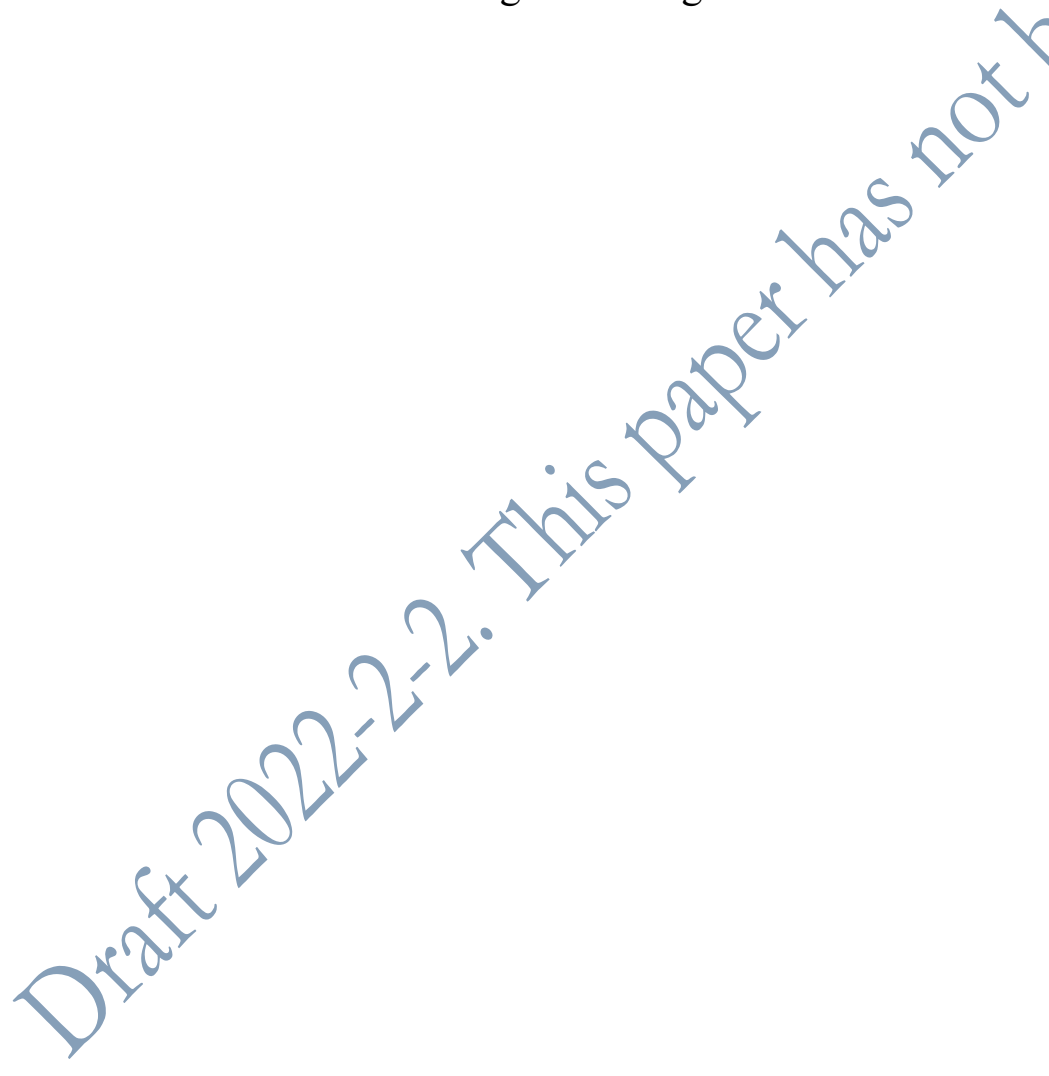

Keywords: Obligations; Identity; Responsibility 


\section{Do Obligations Follow the Mind or Body?}

Suppose someone owes you $\$ 100$, but then undergoes a large transformation. What happens to that $\$ 100$ debt? A common answer given in the philosophy of personal identity is that the later person still owes you the debt, but only if they can be considered "the same person". If the transformation is truly radical, we might think that the later person is not the same person as the one who owed you the debt; the person who owed the debt is no longer around

What might constitute such a truly radical transformation is a centralquestion of personal identity. What makes you the same person as your past and future selves?Philosophers have proposed two primary classes of answers to this question (Shoenaker \& Tobia, 2019). On the mental continuity view, identity persists because past andfuture selves share the same mind. On the biological continuity view, identity persistencerresults from continuity of the body.

As the opening debt example suggests, questions about personal identity are connected to questions about inter-temporal obligations. If certain changes make someone a different person, this may have implications for the obligations of the former person (which are not obviously owed by the new person). Our aim in this paper is to probe lay intuitions about identity by understanding what péple believe happens to our obligations in cases of possible identity change.

Traditionally, philosophers evaluate answers to the personal identity questions by conducting thought experiments. In John Locke's (1689/1905) famous example of the Prince and the Cobbler, Locke invites us to imagine a Prince, whose consciousness enters the body of a Cobbler. He offers this thought experiment to elicit a shared intuition: The person with the 
Prince's consciousness and Cobbler's body is the same person as the Prince. Is this intuition shared by laypeople?

There are many thought experiments about personal identity, some of which have been taken to support the mental continuity view and others that support the biological continuity view (Williams, 1970). Experimental studies have also been brought to bear on what properties affect lay attributions of personal identity (Nichols \& Bruno, 2010; Strohminger \& Nichols, 2014, 2015; Tobia, 2015; Turri \& Weaver, 2018).

One debate that has emerged from these studies concerns thesignificance of lay participants' judgments about these test cases. In many experiments, participants report their agreement with metaphysical non-identity statements like "John is no longer the same person" (Nichols \& Bruno, 2010; Strohminger \& Nichols, 2014, 2015; Tobia, 2015; Turri \& Weaver, 2018). But some critics have suggested that laypeople do not really mean to endorse non-identity (Starmans \& Bloom, 2018). Participants agreeing with these statements may be using hyperbole, intending to communicate something closer to "he's not himself today" than "he's now a metaphysically different person."

A novel way of advancing this debate is to study lay views about obligations. In the philosophy of identity, obligations play a key role. For example, Locke was interested in identity as a metaphysical question, but also because identity is a forensic relation. Identity helps us keep track of obligations. Why does he (and not someone else) owe you money? Because we believe he is the same person as the man to whom you originally loaned money.

Here we study laypeople's views about obligations, to provide new evidence about whether lay endorsement of "identity change" reflects mere hyperbole or a deeper commitment. 
If statements like "he is not the same person" are mere hyperbole, then laypeople's judgments about obligations in those cases should not be affected. But if those identity statements reflect a deeper commitment, then they should parallel judgments about obligations. Thus, what happens to obligations are another way of understanding identity relations.

We use a novel experimental paradigm to assess intuitions about cases in which mind and body diverge. This allows us to test whether participants judge that obligations (a) folłow the mind, (b) follow the body, (c) are split between both mind and body, or (d) disappear (as happens with debt after estates are settled when someone dies). We also test the same options for intertemporal obligations, allowing us to assess whether lay identify judgment carries commitments about moral and legal obligations.

Our investigation builds upon previous investigations by speaking to lay judgment of obligations, assessing whether laypeople evalưate obligations similarly to identity. We also increase the number of possible persons (continuers) to whom the obligation/identity can be assigned by introducing a novel braip transplant scenario. Finally, we extend the work to professional accountants, fawyers, and bank managers to evaluate how people with relevant professional experience regarding the continuance of obligations evaluate such questions about obligation transfer and the possible legal standing of identity.

Study 1 is a preregistered conceptual replication of previous work on identity change, and tests whether obligations may, for some people, follow the physical body and not 'identity' or the mind. In fact, it is possible that there is not one unified way people think about obligations, but different people systematically use different criteria when deciding between obligations following the mind or the body. This possibility is explored in Study 2a, while in Study $2 \mathrm{~b}$ we 
test which individual differences may predict variance in such beliefs (see also SOM). Finally, we test these cases on professionals who have experience in the transfer of obligations of persons over time, including accountants, estate lawyers, and bank managers.

\section{Study 1}

Study 1 first begins by replicating previous work on when people believe somegne would lose their identity. We do this to ensure the basic phenomenon can be built upon reliably, testing whether people believe someone who has lost their sense or morality is interpreted as 'no longer the same person' (Strohminger \& Nichols, 2014). We extend this work by asking what people believe happens to the obligations the person had, if someone is 'no longer the same person', are they free from previous obligations?

\section{Methods}

Participants were 289 Americans fecruited from Amazon Mechanical Turk (mTurk) with a $95 \%$ approval rating or higher, who had completed no more than 500 studies. They also could not have completed one of our previous studies on this topic. The study was preregistered at https://osf.io/cpztq.

Participants began by reading the following information about a person named "J----". No actuar name was given to help ensure participants would not interpret information about the individual from their name. Whether the vignette was about a man or a woman was randomly assigned between participants. Full wording for all scenarios is available at https://osf.io/j9q6e/.

Please consider the following hypothetical scenario about a woman named J---: Note that this information comes from a list of information about J----. We are only showing you a random subset of information about J----. 
Ever since J---- was born, it was clear that there was something distinctive about her personality. She sometimes did bad things to other people, but deep down in her very essence, she was a fundamentally good person. At the very core of her being, she had a profound compassion for other people and a genuine concern about their well-being.

Last Monday, J--- went to the bank and took out a loan for $\$ 10,000$. As J---- was driving home from the bank, she was going faster than normal. She was pulled over and was given a speeding ticket.

As a manipulation check, participants then rated J---'s true self as $1=$ Fundamental1y Evil to $7=$ Fundamentally Good. Since all participants are told the person is Fundamentally Good, we consider anything below a 5 a failure of attention. $36 \%$ of the sample farled this attention check. As we did no preregister whether we would drop these participants for the analysis, however, we kept those participants in the study. We did, however, preregister an exploratory moderation test. This moderation was not statistically significant $(p=.402)$.

On the next page, participants read thelfollowing story (adapted from Strohminger \&

Nichols, 2014):

One day as she is walking down the street, J--- sustains a severe head injury from construction equipment accidentally being dropped on her head. Her only chance for survival is participation in an advanced medical experiment called a Type 2 transplant procedure. It is the year 2049 and scientists are able to grow different parts of the brain if they become damaged. A stock of brain tissue is kept cryogenically frozen to be used as spare parts in the event of an emergency. In a Type 2 transplant procedure, a team of doctors removes the damaged parts of the brain and carefully replaces it with the stock brain tissue. The damaged brain tissue is destroyed after it has been removed. After the operation, all the right neural connections between the old brain and the replacement brain tissue have been made. The doctors test all physiological responses and determine that the patient is alive and functioning. The doctors scan the brain of the transplant recipient and run some standard psychological tests.

In the memory loss condition, participants learn the individual has forgotten how to swim:

They discover that the transplant recipient thinks and acts the same way as before the accident, except she has forgotten how to swim. 
While in the morality loss condition participants learn the individual has lost their moral conscience:

They discover that the transplant recipient thinks and acts the same way as before the accident, except she has lost her moral conscience - she is no longer capable of judging right from wrong, or being moved by the suffering of others.

On the next page, half of the participants were asked the following question about personal continuity:

Please rate which of the following you believe to be true about the fransplant recipient: After the transplant recipient wakes up, they are: [A completely different person than before the transplant $=4$, A somewhat different person than before the transplant $=3$, Somewhat the same person as before the transplant $=2$, Completely the same person as before the transplant $=1$; participants did not see any numbers].

Only half of participants were asked this question to prevent the possibility that being asked the question would itself influence people's beliefs on the obligation question. On the next page, all participants were asked whether the transplant recipient has to pay the speeding ticket, and pay back the bank loan (both questions as a binary choice: yes/no).

\section{Results}

We find that loss of moral conscience leads a person to be judged as having changed more than when theylose a type of memory, consistent with prior research (Strohminger \& Nichols, 2014). For morality loss vs. memory loss, there was a 2.8 log odds decrease in belief that $\mathrm{J} \rightarrow-$-Cwas the same person $(95 \% \mathrm{CI}=-3.62$ to -1.97$)$. Treating the data as continuous instead of ordered-categorical leads to the same conclusion $(\beta=-.59, p<.001$; Gomila, 2021). Having replicated the basic finding that losing one's moral sense leads to an especially large disruption of personal identity, we test whether this changed person is also less responsible for the earlier person's obligations. 
$87 \%$ of participants believed the individual still had to pay back a loan, and $92 \%$ of participants believed the individual still had to pay a speeding ticket. Neither of these decisions was altered by the type of mental faculty that was lost (both $b$ 'sprobit $(287)<.05$, both $p$ 's $>.77$ ), nor moderated by whether participants were asked about identity change before answering the obligations question (both $p \mathrm{~s}>.1$ ). It seems that people can endorse belief that someone has become a completely different person without believing that this eliminates all of theif prior obligations.

\section{Study 2a}

One way to explain the dissociation between identity and obligation in Study 1 is that people are interpreting the question about someone becoming a different person as referring to the degree of features changed (qualitative identityrchange) rather than whether these are two separate people (numerical identity change; Starmans \& Bloom, 2018; Dransieka, Nichols, \& Strohminger, 2021).

Alternatively, people might believe that someone's numerical identity has changed, while also believing that obligations remain intact - because the physical body is what carries the obligation. Our next series of studies investigates this possibility. In this study (and Studies 2b and 3), we present participants with scenarios involving two plausible continuers, one continuer that shares the original person's mind and another that shares the original person's body.

\section{Methods}

Participants were 300 Americans recruited from mTurk. This study was preregistered prior to data collection at https://osf.io/6jrph. 
All participants filled out an attention check, which was administered to increase participants seriousness and data quality (see Oppenheimer et al., 2009). No participants were removed based on the attention check, consistent with our preregistration plan. On the next page, participants read a vignette that described either a man or a woman (as with Study 1). For full study materials see https://osf.io/cywz2/. Participants were randomly assigned to one of three conditions, designed to measure three types of obligation: Loan, Charity, or Tax penalty. In the loan condition participants read the following:

Please consider the following hypothetical scenario about a woman named Jane.

Jane took out a $\$ 2,000$ loan from her bank. As she is driying away from the bank, she is speeding down the highway. She gets into a terrible caraccident with Anne, who was also speeding. Both women fall into a coma, the doctors believe that neither woman will survive. The doctors decide to try an experimental procedure, they attempt a brain transplant between Jane and Anne. Since neither woman has any family and they were about to die, the doctors continue with the surgery. They transplant Jane's brain into Anne's head, and Anne's brain into Jane's head. The transplant is a success. What is more, after the surgery, both women wake up from their comas. Once the women wake up, the doctors test all physiologicatresponses and determine that both transplant recipients are functioning well. There,are no negative side effects from the operation.

In the charity condition, participants read the same but learned the person had promised $\$ 2,000$ to a local charity. In the tax penalty condition, participants read the same but learned the person was fined \$2,000 for cheating on their taxes. All participants were asked the following:

Both Jane and Anne have their bank accounts at the same bank. The bank needs to make the withdrawal to [have the $\$ 2000$ loan paid back/donate the $\$ 2000$ promised to the charity/pay the IRS \$2000].

Before the transplant, Jane had bank account \#J09876. Before the transplant Anne had bank account \#A54321. Now Jane's body has Anne's brain in it and Anne's body has Jane's body in it.

Which account should the bank take the money out of and how much? You may choose any amount from either, both, or neither bank account. 
Participants gave their response on two sliders, one labeled "\#J09876" and the other "\#A54321". Both sliders went from $\$ 0-\$ 2,000$, and were presented in randomized order between subjects.

\section{Analysis Plan}

Following our preregistration plan, we calculated participant responses by dividing the amount given to the body by the total amount assigned by the participant across the two bank accounts. So if a participant assigned the full obligation to the body, their score would be 1; if they split the difference between the two, their score would be 0.5 ; if they fook $\$ 1,500$ from the body's account and $\$ 500$ from the mind's account, they would be scored as 0.75 ; if all money came from the mind's account they would be scored as 0 . Responses that took no money from either account were given no value as they evaporated the obligation; a new variable (denoting whether the obligation was evaporated) was created and they were scored as a 1, with all those who suggested any amount of obligation scored as 0 .

As this data uses proportions, we use a beta distribution for analysis. Because we a priori predicted there would be aninflation of responses fully following the body (i.e. an excess of 1's) and an inflation of responses fully following the mind (i.e. an excess of 0's), we use the zero-one inflated beta estimator in our analyses (Buis, 2010).

\section{Results}

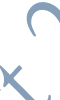

First, we found no evidence that the pattern of results differed by whether it was a loan, a promise to charity, or a tax penalty (all $p s>.08$, see https://osf.io/sqsef/wiki/). Therefore, we collapsed across these conditions and report people's beliefs about the tracking of obligations. 
The data overwhelmingly were clustered on the option that all money should come from the bank account of the body that made the obligation; put simply of people that did not negate the obligation: $129 / 257$ participants $(50 \%)$ believed the money should come out of the bank account tied to the body that incurred it; 53/257 participants (21\%) believed it should come from the mind that incurred the obligation, and the rest split the difference, with the majority (23/257, 9\%) splitting it equally. Thus, participants largely agreed that the obligation rested with the body, not with the mind or somewhere in between $\left(b_{\text {ZOIB_1-inflate }}=.54, p<.001,95 \% \mathrm{Cl}=.26\right.$ to .83 ; see Figure 1).

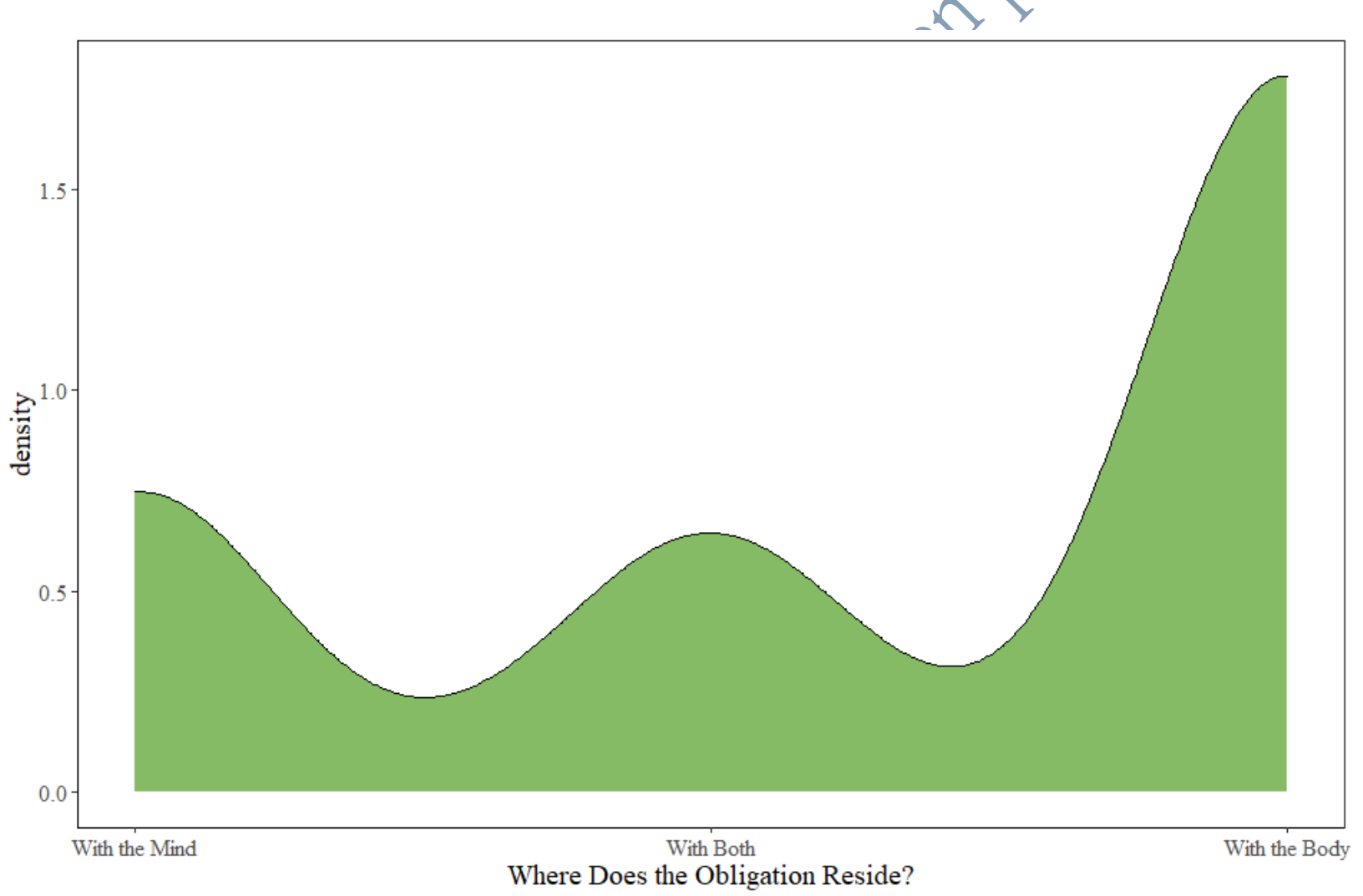

Figure 1: Density plot of responses to whether a financial obligation incurred before someone had their brain swapped with someone else should come from the mind of the person who incurred the fine (which is now in a new body), be shared between the two people, or come from the bank account of the body that incurred it (with a new mind in it).

Thus, we have our first evidence that for some obligations there is indeed an inclination to believe the obligation is tagged to the body that incurred it, regardless of whose mind is inside. 
This can help explain the findings in Study 1, where participants indicated that mental changes could render someone a different person without vitiating their previous obligation. The body, rather than the mind, appears to be the nexus of the obligation, especially when the obligation is a monetary one (as in Study 1).

The results of this study are striking, in that a significant number of people who believe the obligation resides entirely with the body that incurred it regardless of whose mind is inside (hereafter 'body-followers'). One possibility could be participants did not understand or have an opinion about the scenario, and were choosing randomly. We replicateand test possible alternate explanations in the next study.

\section{Study $2 b$}

\section{Methods}

Study $2 b$ was a replication of Study $2 a$ in a larger, more representative sample using additional stimuli and measures tovule oút alternative explanations.

Participants were 1,500 American adults, drawn in a stratified way with unequal probabilities of selection, so that those who complete survey will resemble the nation's adult population (according to the most recently available Current Population Survey, conducted by the U.S Census Bureau) in terms of gender, age, education, ethnicity, race, region, and income. This sampling was handled by the company CriticalMix.

Participants first filled out the same attention check as in Study 2a on separate pages (for full instructions see the SOM at https://osf.io/2vgsa/). Participants read a vignette that was 
gender-matched, as we predicted gender could moderate the results we also randomly assigned people to conditions within gender (see Athey \& Imbens, 2017). Here is a sample vignette:

John was recently found guilty of cheating on his taxes. He was fined \$2000 and given a 20-month prison sentence, to be served starting one month from now.

As he is driving away from the courthouse, he is speeding down the highway. He gets into a terrible car accident with Adam, who was also speeding.

Both men fall into a coma, the doctors believe that neither man will survive.

The doctors decide to try an experimental procedure, they attempt a brain transplant between John and Adam. Since neither man's family can be contacted and they were about to die, the doctors continue with the surgery.

They transplant John's brain into Adam's head, and Adam's brain into John's head. The transplant is a success. What is more, after the surgery, both men wake up from their comas.

Once the men wake up, the doctors test all physiological responses and determine that both transplant recipients are functioning well. There are no negative side effects from the operation.

Participants were then asked four questions, each on a separate page, in randomized order. One was on who has to pay back a fine, one yas on who has to spend time in prison, one was on who gets to drive the car the accident was in, and one was on who gets to sleep with the spouse of one of the individuals. Here is the question about prison time:

The guilty verdict was 20 months in prison. The judge needs to decide who will spend what time in jail.

Now John's body has Adam's brain in it and Adam's body has John's brain in it.

Who should spend how much time in jail? Should it be John's body with Adam's brain in it? Should it be Adam's body with John's brain in it? You may choose any amount of months below from either, both, or neither.

Participants gave their response on two sliding scales ranging from 0-20. One anchor was labeled "John's body with Adam's brain in it" and the other "Adam's body with John's brain in it”. The wording of the other three questions may be found at https://osf.io/2vgsa/. 
Finally, participants filled out two comprehension check questions. This study was preregistered at https://osf.io/t9vdf.

\section{Results}

$77 \%$ of participants answered both comprehension check questions correctly. Our analyses include only those who passed both comprehension checks, but additional apalyses show the results do not meaningfully change when including all participants.

The results largely replicated those in Study 2a. Across all four DV $\$$, there was a strong trimodal pattern with people split between whether the obligationfollows the mind, follows the body, or is split between the two. Among those who passed both attention checks, the first scenario people saw (due to inconsistent order effects, see https://osf.io/9e8tj/wiki/home/ for more details), we saw notably fewer body-followers in this replication than the first study (see Table 1).

Table 1: Percent of Participants whochose the obligation fully followed the mind or fully followed the body

\begin{tabular}{lrr} 
Obligation & $\begin{array}{l}\text { \% Fully Agreeing } \\
\text { the Mind in the } \\
\text { New Body }\end{array}$ & $\begin{array}{l}\text { F Fully Agreeing } \\
\text { the Body with the } \\
\text { New Mind }\end{array}$ \\
\hline Who Pays the Fine? & $45 \%$ & $26 \%$ \\
Who Goes to Jail? & $25 \%$ & $11 \%$ \\
Who Drives the Car? & $26 \%$ & $21 \%$ \\
\hline
\end{tabular}

Thus, overall, we still saw the trimodal pattern of obligations following the mind, the body, or being split between the two in a large sample drawn to resemble the U.S. adult population. While in Study $2 b$, ensuring that participants understood the scenario decreased the 
number of people who believed the obligation rests entirely with the mind compared toStudy 2a, it in no way eliminated it. This suggests that people systematically differ in their intuitions about whether obligations track the mind or the body. The question now becomes: which individuallevel factors predict this difference?

With that possibility in mind, we ran yet another replication of this brain swap and obligations paradigm, testing intuitions about identity and obligations, also measuring several potential individual difference factors that may predict responding.

\section{Study 3}

\section{Methods}

Participants were 1,500 American adults drawn in the same manner as in Study $2 b$ to match the demographics of the U.S. adult population with the added restriction that anyone who participated in Study $2 \mathrm{~b}$ could not take part in this study.

Study 3 was similar to Studies $2 \mathrm{a}$ and $2 \mathrm{~b}$ in that it portrayed a brain-body swam and measured intuitions about obligations following the swap.

To further ensure participants understood the scenario, we included "before" and "after" drawing depicting the swap to help participants understand that brains had been moved between two bodies.

Participants were randomly assigned to fill out the essentialist beliefs scale (Horne \& Cimpian, 2019) and the dualism scale (Nadelhoffer et al., 2014) either before or after responding to the swap scenario (for open materials see https://osf.io/3zxgy/wiki/home/). 
Half of the participants read a scenario that was described as a 'brain swap' (as in the previous studies). The other half learned about the same case, though it was described as a 'body swap' — where the brains stayed put and the bodies were moved. This condition was added to test the role of framing what is the originating (versus transferred) part of the person in what people assign priority to.

In addition to collecting responses on who has to pay the fine, we added another type of obligation. Participants were told one of the individuals had recently purchased a 30 -day gym membership and some days were left. This was to further ensure our results were not idiosyncratic to the specific obligations we have investigated so far Half the participants answered who had to pay the fine, and the other half answered who had access to the gym membership.

At the end, education level was recorded and coded as years of education (following Rietveld et al., 2014). This study was preregistered at https://osf.io/yjcps.

\section{Results}

We found no consistent effect of referring to the procedure as a body swap versus a brain swap (for analysis, see https://osf.io/uxgck/wiki/). This suggests people were not deciding that the obligation followed the body simply because the body stayed put while the brains were moved. We therefore collapsed this factor for all analyses, consistent with our preregistration plan.

There was a tendency for more educated people to be more likely to dismiss the fine $(b=$ $.005, p=.038,95 \% \mathrm{CI}=<.001$ to .01$)$ though this was not replicated in the gym-membership 
obligation $(b=-.002, p=.261)$. None of the other individual differences significantly predicted who would dismiss the obligation entirely. Thus, the remaining analyses focus on where people think the obligation resides if they think the obligation remains.

For the fine, the more someone believes in mind/body dualism the more likely they were to believe the obligation tracks the body $(b=.04, p=.035,95 \% \mathrm{CI}=.003$ to .08$)$. In addition, the more someone believes in essences, the more likely they were to believe the obligation tracked the body $(b=.15, p=.001,95 \% \mathrm{CI}=.06$ to .25$)$. Likewise, the more someone believed in essences, the less likely they believed the obligation stays with the mind $(b=-.2, p<.001$, $95 \% \mathrm{CI}=-.25$ to -.14 ). No other relationships were significant (see full output at https://osf.io/uxgck/wiki).

Concerning who gets to use the gym membership, we again found mind-followers were the least likely to believe in essences $(b=-.13, p<.001,95 \% \mathrm{CI}=-.18$ to -.08$)$. We also found that the best-educated people were the most likely to be mind-followers $(b=.01, p=.045,95 \%$ $\mathrm{CI}=<.001$ to .02 ; see Figure 2 ). This offers one possible explanation of why the idea of an obligation tracking the physical body has received comparatively less support among philosophers (Bourget \&Chalmers, 2014); the higher an education one has, the more likely one is to believe obligations track the mind that incurred them. 


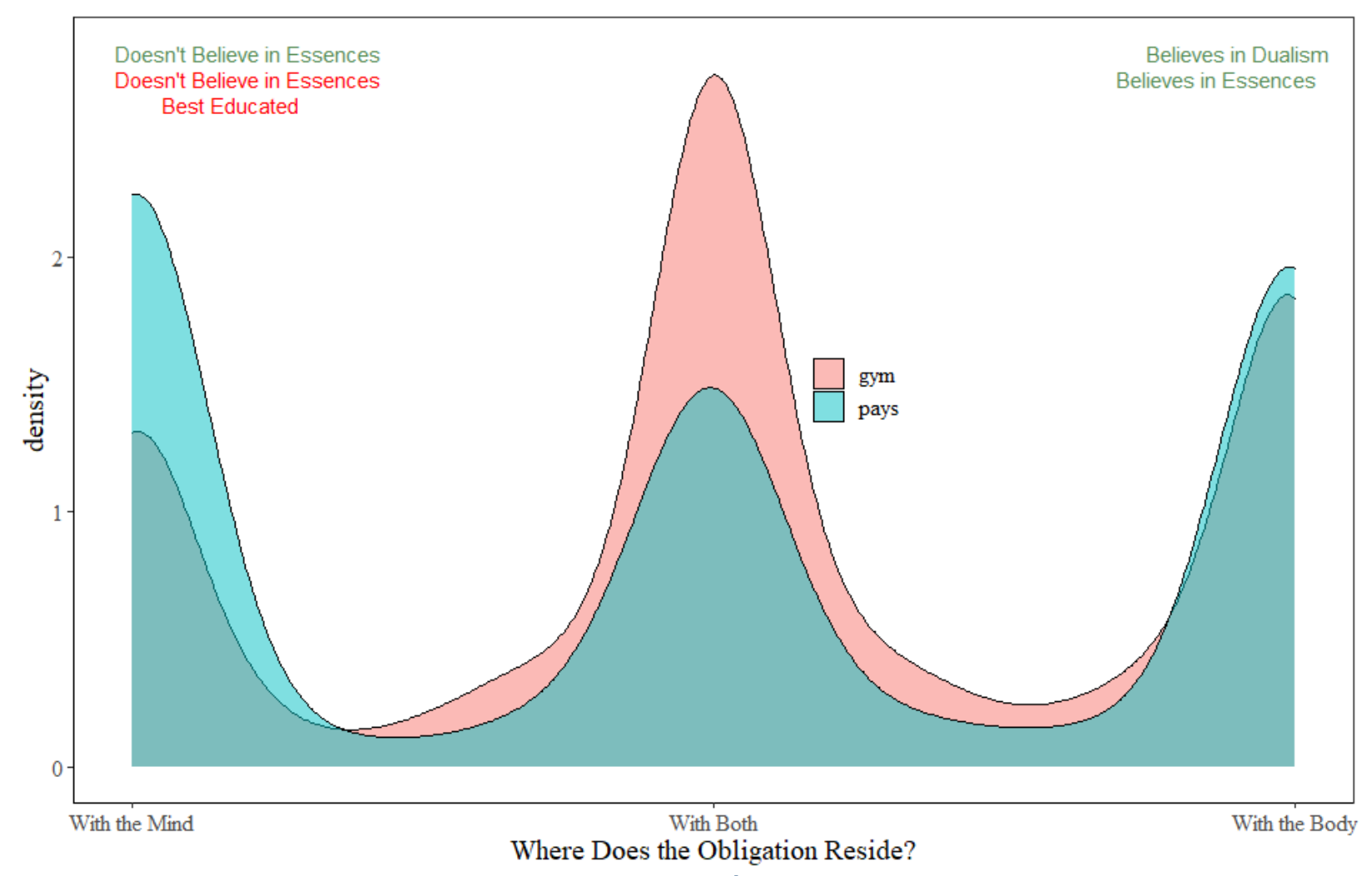

Figure 2: Distribution as a density plot of choices in abrain swap scenario about whether the obligations follow the body (rightmost in graph), obligations follow the mind (leftmost in graph), obligations are split between the two (middle peak) or somewhere in between.

Thus, Study 3 revealed some important new insights about identity intuitions. The variety of views about obligations observed in previous studies are not an error or random response, but are systematically related to how individuals think about essences, mind/body dualism, and to some extent their education.

The role of education in generating such intuitions gives us some hint that the lay populace may have very different intuitions than those whose training requires a nuanced understanding of obligations. To investigate this, Study 4 measured identity-swap intuitions among professionals with expertise in tracking obligations.

\section{Study 4}


While the results of Study 3 showed the highest educated people were most likely to be mind-followers, professionals with training and experience related to inter-temporal obligations may see things rather differently. This provides the first use of such professional groups in these types of scenarios.

\section{Methods}

Study 4 was a direct replication of Study 3, with the following changes, the included a new within-subjects obligation, who would have to fulfill a work contract that was previously signed. We also included measures of how confident people were intheindecisions of who would have to pay back the obligation, and a direct question about the identity of the individuals. Finally, we ran the study simultaneously in a naïve sampleand in a sample of professionals who have experience tracking obligations; these professionals were bank managers, lawyers, and accountants.

Lay participants were 679 mTurkers from the United States with a 95\% approval rating or higher and having participants in no more than 500 previous studies, nor in one of our previous studies on this topic. Professional participants were 576 professionals who were Lawyers (Probate and Estate Administration, Healthcare/Health Law, Tax Law, or Banking Law), Accountants (Estate Planning, Medical or Hospital accounting, Income Tax preparation and planning (for others), or Bank Accounting), and Bank Managers.

Professionals were first asked about their relative expertise, and those not fulfilling one of our relevant categories were excluded from participating in the study. Participants received the fine dependent measure from Study 3 and the work contract dependent measure in randomized 
order (for full materials, see https://osf.io/aevwt/wiki/home/). For the work contract obligation, participants read:

Before the accident, John had signed an employment contract stating that John would work at a new company for 40 hours each week. Adam did not have any employment contract with that company.

Once both patients recover from surgery, for how many hours a week is each responsible to work for the new company, according to the employment contract? You may choose any amount of hours from either, both, or neither of them.

Response options were two sliding scales, presented in random order, with anchørs at one end labeled John's body with Adam's brain in it and the other anchor labeled Adam's body with John's brain in it. After the scenarios and questions, participants were asked the level of confidence they had with their answer on a 5-point scale (following Mastrandrea et al., 2010).

For the explicit identity judgments, participants were asked (following Weaver \& Turri, 2018):

John's body with Adam's brainin it is wheeled into the West Recovery Room while Adam's body with John's brain in it is wheeled into the East Recovery Room.

Where is John?

Participants could select either in the West Recovery Room, in the East Recovery Room, in both Recovery Rooms, or in neither Recovery Room. Response options presented in random order

Participants responding 'in both Recovery rooms' were asked:

To what extent is John in the West Recovery Room and to what extent is John in the East Recovery Room? 
You can select any percent in each room but the total must equal 100\% [John is in the East Recovery Room, John is in the West Recovery room, presented in random order]. Participants were also asked their confidence in their answer to the explicit identity question. Finally, we asked participants their highest level of education. This study was preregistered at https://osf.io/tzk8w.

\section{Results}

Professionals were less likely to believe in essences than lay participants $(\beta=-.13, p<$ $.001,95 \% \mathrm{CI}=-.19$ to -.07$)$. Professionals also tended to believe more in mind/body dualism, though the effect was small and statistically non-significant $(\beta=.05, p=.06)$. Based on the results of Study 3, as our professional groups were better educated and less likely to believe in essences, we might expect these professionals to be more likely to believe the obligation tracks the mind.

\section{Who Should Pay the Fine?}

Professionals showed targely the same trimodal pattern as lay people. Professionals were more likely to assign the fine to the body than the general population and less likely to split the difference between the two accounts $\left(b_{\text {ZOIB }}=.43, p=.007,95 \% \mathrm{CI}=.12\right.$ to .74$)$. They were no more likely to say the obligation evaporated $\left(b_{\text {logit }}=.06, p=.892\right)$. These results do not change when conditioning on the belief in mind/body dualism (i.e. adding dualism as a covariate)..

\section{Who Gets to Work for the Company?}

Concerning who should work for the company, the results were largely the same. Both groups had a trimodal pattern, with professionals more likely to say the body of the person who 
signed the work contract should fulfill the obligation — even with someone else's brain inside of it $\left(b_{\mathrm{ZOIB}}=.38, p=.021,95 \% \mathrm{CI}=.06\right.$ to .7$)$. These results likewise do not change when conditioning on beliefs in mind/body dualism.

\section{Explicit Identity Judgment}

Explicit identity judgments followed the same pattern as obligation judgments. Overall, professionals were more likely to say that John was in the room with his body $40 \%$ in professionals vs. $32 \%$ in laity, $b=.59, p=.001,95 \% \mathrm{CI}=.25$ to .92$)$. Giventhat there was a strong covariance between people's judgments of identity and obligations,for both paying the fine $\left(r_{\mathrm{S}}=.45, p<.001\right)$ and who should fulfill the work contraet $\left(r_{\mathrm{S}}=.44, p<.001\right)$, this should be unsurprising. Furthermore, the covariance of identity judgments and obligations was the same in both groups (not moderated by Professional statas; $p=.125$ for pay and $p=.122$ for work).

Compared with laypeople, lawyers, aceountants, and bank managers were more likely to endorse the view that the body, not the mind, is where identity and obligations reside. There were no differences among the three different professional groups (see https://osf.io/cw5qg/wiki/).

We have now seen that in a hypothetical brain swap case, a substantial number of people believe the obligation would stay with the physical body that incurred it, not in the mind. Furthermore, among those in professional careers directly relating to the tracking of obligations, the tendency to track the obligation with the body was enhanced, despite being better educated and less likely to believe in essences (both of which would predict tracking the obligation to the mind). 


\section{General Discussion}

Across a series of studies, we found the relationship between identity and obligation varies substantially depending on both the number of continuers and the individual. In Study 1, changes in identity largely failed to impact assessments of obligation. In Studies $2-4$, we found a more complex pattern of results. While perceptions of obligation largely followed peoplés assessments of identity (as in Study 4), their assessment of the continuation of both varied markedly.

Some people believe obligations and identity judgments follow the body, others believe they follow the mind, and still others split obligations between the mind-continuer and bodycontinuer. Despite strong philosophical arguments favoring identity and obligations tracking the mind (e.g. Locke, 1689/1905), lay judgments are notably more varied, and in our studies many people believed obligations and identity actually tended to follow the body with someone else's mind inside it. Study $2 \mathrm{~b}$ demonstrates that this was not a function of participant misunderstanding the scenario. Studies 3 and 4 find that the tendency to believe obligations and identity follows the body-are predicted by specific beliefs about essences, mind/body dualism, and education levels.

Whether one is a mind-follower, body-follower, or splitter was predicted by several psychologieal traits, suggesting that participants' decisions were not arbitrary. Furthermore, the use of comprehension checks did not moderate the results, so the variety of assigning obligations were not due to participants not understanding the scenarios. We found physical essentialism and mind/body dualism predict body-following; while the best educated participants are more likely 
mind-followers and the least educated are more likely splitters. The professional experts were more likely to be body-followers.

Essentialism predicted the belief that obligations track the body. This may seem mysterious, until we consider that much of essentialism has to do with tracking a physical (if invisible) properties. Here is a sample item from the Beliefs in Essentialism scale: Trying on a sweater that Hitler wore, even if it was washed thoroughly beforehand, would makê me very uncomfortable (Horne \& Cimpian, 2019). If someone believes that essencesåre physically real in this way, it makes sense that they would also believe that obligations and identity go with the body.

Consideration of specific items in the Mind/body Dualism Scale (Nadelhoffer et al., 2014) similarly offer insight into its relationship with the continuity of obligation in this study. Items like Human action can only be understood in terms of our souls and minds and not just in terms of our brains, indicate that for mind/body dualists, a person is not reducible to their brain. Accordingly, for mind/body dualists, though the brain may change, something else remains in the body that maintains both identity and obligations.

- The results here provide evidence of the relationship between intuitions about numerical identity andpractical obligations. Participants — whether mind-followers, body-followers, or brain-swap cases, for example, mind-followers were inclined to judge the person with the same mind as the same person and the person with the continuous mind inherits the prior obligations. Body-followers, meanwhile, believe the person with the same body is the same person and retains those obligations and identity, regardless of whose mind is inside. 
These findings help inform debates about how to interpret studies where participants insist that someone is 'no longer the same person' (e.g. Starmans \& Bloom, 2018): are those statements hyperbole, or do they reflect a deeper metaphysical evaluation? Our data suggest a complicated answer. Judgments of obligations depend on some core philosophical positions of the people being asked. Both the extent to which one believes in essences and the extent one believes in mind/body dualism predict how one thinks about identity and obligations. Furthermore, the more educated one is, the more likely one is to believe identity and obligations reside with the mind, not the body. Therefore, it is not as simple as 'lay people believe/don't believe X', we instead must look at which people believe what. This will undoubtedly complicate drawing broad inferences from what all people supposedly betieve or endorse.

Finally, professionals with more experience in tracking obligations differed from other highly educated participants in seeing obligation as following the body. For lawyers, bankers, and accountants, it may be useful to rely on a concrete and easily identifiable objective criterion like the body in assigning identity and obligations.

Contrary to Locke, both professionals and many laypeople do not unanimously endorse a straightforward mind-criferion of identity and obligations; for many, identity and obligation follow the body, no matter whose mind is inside it.

\section{Acknowledgments}

The authors would like to thank Christina Starmans for helpful comments and discussions. Thanks go to Madeline Gross for her help with the drawings used in Study 3 and 4, and John Scully and Bill Scully for their help identifying relevant professional groups. Protzko was supported by a grant from the Fetzer Franklin Fund. 


\section{References}

Athey, S., \& Imbens, G. W. (2017). The econometrics of randomized experiments. In Handbook of economic field experiments (Vol. 1, pp. 73-140). North-Holland.

Berent, I. (2021). Can we get human nature right?. Proceedings of the National Academy of Sciences, 118(39), e2108274118. https://doi.org/10.1073/pnas.2108274118

Buis, M. L. (2010). ZOIB: Stata module to fit a zero-one inflated beta distribution by maximum likelihood," Statistical Software Components S457156, Boston College Department of Economics, revised 08 Aug 2012.

Diamantis, M. E. (2019). Corporate essence and identity in criminal law. Journal of Business Ethics, 154(4), 955-966.

Dranseika V., Nichols S., Strohminger N. (2021). Which kind of sameness? Disambiguating two senses of identity with a novel linguistic task. Unpublished manuscript.

Gomila, R. (2021). Logistic or linear? Estimating causal effects øf experimental treatments on binary outcomes using regression analysis. Journal of Experimental Psychology: General, 150(4), 700-709. https://doi.org/10.1037/xge0000920

Horne, Z., \& Cimpian, A. (2019). Intuitions about personal identity are linked to essentialist thinking in adults and children. Cognition, 191, 103981.

Locke, J. (1905). Locke's essay concerning human understanding (No. 58). Open court Publishing Company.

Mastrandrea, M. D., Field, C. B., Stocker, T. F., Edenhofer, O., Ebi, K. L., Frame, D. J., ... \& Plattner, G. K. (2010). Guidance note for lead authors of the IPCC fifth assessment report on consistent treatment of uncertainties. Accessed at https://pure.mpg.de/rest/items/item_2147184/component/file_2147185/content on April 28, 2020.

Nadelhoffer, T., Shepard, J., Nahmias, E., Sripada, C., \& Ross, L. T. (2014). The free will inventory: Measuring beliefs about agency and responsibility. Consciousness and cognition, 25, 27-41.

Nichols, S., \& Bruno, M. (2010). Intuitions about personal identity: An empirical study. Philosophical Psychology, 23(3), 293-312.

Oppenheimer, D. M., Meyvis, T., \& Davidenko, N. (2009). Instructional manipulation checks: Detecting satisficing to increase statistical power. Journal of Experimental Social Psychology, 45, 867-872. 
Rietveld, C. A., Conley, D., Eriksson, N., Esko, T., Medland, S. E., Vinkhuyzen, A. A., ... \& Domingue, B. W. (2014). Replicability and robustness of genome-wide-association studies for behavioral traits. Psychological science, 25(11), 1975-1986.

Rips, L. J., Blok, S., \& Newman, G. (2006). Tracing the identity of objects. Psychological Review, 113(1), 1-30. https://doi.org/10.1037/0033-295X.113.1.1

Shoemaker, D. \& Tobia, K. (2021). "Personal Identity”, In M. Vargas and J. Doris (eds.). Oxford Handbook of Moral Psychology. Oxford: Oxford University Press.

Starmans, C., \& Bloom, P. (2018). Nothing personal: What psychologists get wrong about identity. Trends in Cognitive Sciences, 22(7), 566-568.

Strohminger, N., \& Nichols, S. (2014). The essential moral self. Cognition, 131(1), 159-171.

Strohminger, N., \& Nichols, S. (2015). Neurodegeneration and identity. Psychological Science, 26(9), 1469-1479.

Tierney, H., Howard, C., Kumar, V., Kvaran, T., \& Nichols, S. (2014). How many of us are there?. In n J. Sytsma (ed.) Advances in Experimental Philosophy of Mind. Continuum Press. 181-202.

Tobia, K. P. (2015). Personal identity and the Phineas Gage effect. Analysis, 75(3), 396-405.

Weaver, S., \& Turri, J. (2018). Personal identity and persisting as many. Oxford studies in experimental philosophy, 2, 213-242.?

Williams, B. (1970). The self and the future. The Philosophical Review, 79(2), 161-180. 